Research Article

\title{
Study on Structural Service Performance of Heavy-Haul Railway Tunnel with Voided Base
}

\author{
Zhiqiang Zhang $\mathbb{D}^{\mathrm{D}}$, Bowen Zeng, Chaolong Dai, and Wanping He \\ Key Laboratory of Transportation Tunnel Engineering, Ministry of Education, Southwest Jiaotong University, \\ Chengdu 610031, Sichuan, China
}

Correspondence should be addressed to Zhiqiang Zhang; clark@swjtu.edu.cn

Received 11 May 2018; Accepted 15 August 2018; Published 11 October 2018

Academic Editor: Qianbing Zhang

Copyright ( ) 2018 Zhiqiang Zhang et al. This is an open access article distributed under the Creative Commons Attribution License, which permits unrestricted use, distribution, and reproduction in any medium, provided the original work is properly cited.

\begin{abstract}
The structural design of heavy-haul railway tunnels still follows the design method of ordinary railway tunnels. Most of them do not take into account the influence of large axle load of $30 \mathrm{t}$ or more, let alone such problems as void of surrounding rock under long-term dynamic loads. In order to analyze the dynamic response of heavy-haul railway tunnels under long-term reciprocating cyclic dynamic loads, considering the factors such as axle load of vehicle body, unsprung mass, and track irregularity, the vibration load time-history curve of heavy-haul railway trains is determined, the three-dimensional dynamics coupling model of dynamic load-tunnel-surrounding rock is established, and the fatigue life of the structure under different void conditions is analyzed based on the S-N curve of concrete. According to the study, the loading, unloading, and vibration caused by train passing will lead to fluctuations in the vertical displacement response of the monitoring point. The peaks and valleys of the response time-history curve correspond to the effect of the train wheels rolling through. When the void is $6 \mathrm{~m}$ wide and $10 \mathrm{~cm}$ thick, the vertical displacement of the inverted arch is increased by about 9 times, the peak velocity of the inverted arch is increased by about 3.8 times, and the maximum principal stress is increased by about $47.3 \%$, compared with the condition without void. With the same void thickness, the vertical displacement and velocity curves of the inverted arch vary significantly with the increase of the void width. The width of the base void has a significant effect on the fatigue life of the structure of heavy-haul railway tunnels. Based on the operation requirement of 100 -year service life, the ultimate void width is $2 \mathrm{~m}$.
\end{abstract}

\section{Introduction}

Heavy-haul railways feature great transport capacity and significant economic and social benefits. They represent the level of a country's freight capacity. Since the 1960s, heavyhaul railways have gradually dominated the railway transportation in various countries. Unlike traditional railways, the under-track structure and surrounding rock of heavyhaul railways will bear greater loads due to the significant increase in the axle load of trains. Combined with a series of factors such as stability of soft surrounding rocks and track irregularity, heavy-haul railway tunnels are more easily damaged under long-term vibration of trains, and new requirements for the structure of heavy-load railway tunnels are therefore put forward. The impact of heavy-haul trains on the base structure is mainly manifested in the increase of the load on the track and the under-track base foundation. Such load is different not only from the static load, but also from the seismic load. It is a reciprocating cyclic load that is applied for a long time. The study on the mathematical expression and time-history curve of the train excitation load is mainly based on field measurements and theoretical analysis. Jenkins et al. [1] established the dynamic analysis model of depressed joint track and defined the two objective special forces in wheel-rail impact vibration: high-frequency impact force P2 and low-frequency response force P1. Lamaran et al. [2] analyzed forced vibration of rail and simulated the train load as the sum of the static load and additional dynamic load associated with wheel weight, rail support condition, sleeper spacing, and vehicle speed. One et al. [3] carried out actual measurements and proved that the wheel-rail acting force is severer in a medium frequency 
range and mainly affects the dynamic response of the vehicle body in a high-frequency range.

The dynamic response of tunnel base structure under such cyclic dynamic load is also a key to the scholars' study $[4,5]$. In the early days when the computational capacity was limited, a reasonable analytical model was the main research approach. Metrikine et al. [6] established a typical plane analytical model and analyzed the response of the structure under constant point load, covariant point load, and random point load by simulating the tunnel in viscoelastic soil with the Euler beam. Balendra et al. [7] established a semianalytical semiplane strain model and adopted the substructure method to reduce the complexity of the problem. Forrest et al. $[8,9]$ established a pipe-in-pine model and analyzed the vibration effect during train passing by taking the outer elastomeric pipe with infinite radius as the stratum, the thin inner pipe as the lining, and the floating plate inside the thin shell as the filling (the plate and the shell are connected by a spring). The model was later improved by Hussein et al. [10]. With the improvement of computer performance and computational capacity, more and more scholars have proposed numerical models suitable for train vibration. The finite element method was widely used to study the tunnel vibration response [11-13]. Because both finite element and boundary element have their own advantages in dealing with lining structure and infinite soil, Peng et al. $[14,15]$ carried out numerical simulation for the underlying concrete structure of tunnel under the impact load of train vibration with the nonlinear dynamic finite element theory and predicted the service life of the underlying structure by using the Tepfers concrete singlelogarithmic fatigue equation. A finite element-boundary element coupling model was established to analyze the impact of train vibration on adjacent buildings [16-18].

Under long-term vibration loads of heavy-haul trains, the tunnel base will inevitably be subjected to cumulative fatigue damage or even failure and void of surrounding rock. Due to the large discreteness of concrete and many other influence factors, there is no effective method to predict the fatigue life of concrete, and existing studies usually predict the fatigue life of concrete with the cumulative damage theory. Bazant et al. [19] and Mazars et al. [20] established the early scalar fatigue damage model for concrete with theories related to fracture mechanics. Fardis et al. [21] further optimized the model and adapted it to concrete strain softening by modifying the flexibility matrix equation of bounding surface. Abu-Lebdeh et al. [22] proposed a constitutive model considering the plasticity of concrete and the damage boundary. The model simulates the state of stiffness degradation and softening of concrete under the cyclic action multiaxial stress. Wu et al. [23] introduced tensile and shear damage variables to describe concrete stiffness degradation at a macroscale and derived the mathematical expressions of plastic strain evolution law and Helmholtz free energy. Based on the theoretical system of Helmholtz free energy, Peng et al. [24] conducted an experimental study for concrete of inverted arch under different vibration amplitudes in a coupling environment of static and cyclic loads and figured out the static load level that can cause concrete damage and failure as well as the quantitative expression of damage evolution trends at different stages; Wang et al. [25] conducted the impact compression test for many times on 5 types of support concrete of different ages with SHPB test equipment. The peak damage at stable age indicates that the statistical damage model of the Weibull distribution can well reflect the damage characteristics of the material.

During the service of heavy-haul railway tunnels, the fatigue damage and void of surrounding rock of the base structure are not independent of each other but are concomitant, and there are incentive and superposition effects between the two. Structural damage [26] will lead to decrease of stiffness and greater deformation under stress, which will incur greater load and compression on the surrounding rock of the base as well as continuous accumulation of plastic deformation [27, 28] and aggravated void of the surrounding rock, thus changing the support conditions of the structure and causing greater damage to the structure subjected to upper dynamic loads. This paper studies the characteristics of the full-cycle temporal-spatial response of the base structure of heavy-haul railway tunnels under repeated impact by establishing a three-dimensional numerical dynamics coupling model of dynamic load-tunnelsurrounding rock and predicts the fatigue life of the tunnel structure under different void conditions by carrying out failure evaluation for the base structure under damage-void excitation based on the $\mathrm{S}-\mathrm{N}$ curve of concrete. It is found that during the service of heavy-haul railway tunnels, the presence of voided base has a significant influence on the displacement and velocity response of the lining structure as well as the distribution and magnitude of the principal stress on the lining. In addition, the void width of the base has a great influence on various indicators of the lining structure, while the influence of void thickness is minor.

\section{Numerical Model of Heavy-Haul Railway Tunnels}

2.1. Determination of Train Excitation Load. The vibration of a train is under the joint influence of the train and the track. It is mainly caused by the abrasion of wheels, the state of rail joints, and geometric irregularity. On the vertical longitudinal plane of the wheel-rail system, there are a wide variety of vibration sources: local unevenness of the existing rail surface, such as rail head crushing or rail surface peeling, and periodic system irregularities, such as waveform track, corrugation, and eccentric wheels. Particularly, abrupt irregularities are more common at such places as depressed joints, joints with height difference, large rail joints, and welds. In addition, defects such as loose sleepers or hardened ballast bed may occur to the under-track foundation, resulting in dynamic irregularity of uneven elasticity, and thereby creating an excitation load.

Considering the influence factors of train vibration and combined with the management value of track geometric irregularity in the UK, the vertical excitation force of the train can be simulated by an excitation function $[1,29]$. This function takes into account the axle load of vehicle body, 
unsprung mass, track irregularity, driving speed, load periodicity, movement and combination of loads, and the effect of rails and sleepers on the dispersion and transmission of loads, as shown in the following formula [30]:

$$
F(t)=p_{0}+p_{1} \sin \left(\omega_{1} t\right)+p_{2} \sin \left(\omega_{2} t\right)+p_{3} \sin \left(\omega_{3} t\right),
$$

where $p_{0}$ is the static load of wheels and $p_{1}, p_{2}$, and $p_{3}$ are the vibration loads corresponding to the typical values of (1)-(3) in Table 1. Taking $M_{0}$ as the unsprung mass of the train, then the corresponding vibration load should be

$$
p_{i}=M_{0} a_{i} \omega_{i}^{2}, \quad(i=1,2,3),
$$

where $a_{i}$ is the typical rise of arch and $\omega_{i}$ is the circular frequency of irregularity vibration wavelength at corresponding speed, corresponding to (1), (2), and (3) in Table 1, respectively. The formula is

$$
\omega_{i}=2 \pi v / L_{i}, \quad(i=1,2,3),
$$

where $v$ is the running speed of train and $L_{i}$ is the typical wavelength corresponding to (1), (2), and (3) in Table 1.

The management value of track geometric irregularity in the UK is shown in Table 1 [31].

When calculating the train load, the unilateral static wheel weight should be taken: the vehicle load is $150 \mathrm{kN}$ and the unsprung mass is taken as $M_{0}=1200 \mathrm{~kg}$. Generally, the speed of heavy-haul railways does not exceed $100 \mathrm{~km} / \mathrm{h}$. Therefore, the vibration load of the train at a speed $\nu=100 \mathrm{~km} / \mathrm{h}$ is taken into account for the simulation of the time-history curve of train excitation load, as shown in Figure 1.

\subsection{Material Mechanics Parameters and Boundary Condition}

2.2.1. Material Mechanics Parameters. During dynamic analysis, the rock mass medium is taken as an ideal elasticplastic material which follows the Mohr-Coulomb strength criterion, and the large-strain deformation mode is adopted. The yield function is

$$
\left\{\begin{array}{l}
f^{s}=\sigma_{1}-\sigma_{3} N_{\phi}+2 c \sqrt{N_{\phi}}, \\
f^{t}=\sigma_{3}-\sigma^{t},
\end{array}\right.
$$

where $\sigma_{1}, \sigma_{2}$, and $\sigma_{3}$ are the principal stresses of the material ( $\sigma_{1} \leq \sigma_{2} \leq \sigma_{3}$, and the compressive stress is negative); $c$ is the cohesive force; $\sigma^{t}$ is the tensile strength of the material; and $N_{\phi}$ is related to the internal friction angle, and its expression is

$$
N_{\phi}=\frac{1+\sin \phi}{1-\sin \phi}
$$

Shear damage occurs when the stress on a certain point within the rock mass is positive $\left(f^{s}>0\right)$; tensile damage occurs when $f^{t}>0$.

The potential function in the Mohr-Coulomb model is described by $g^{s}$ and $g^{t}$, defining the shear plastic flow and tensile plastic flow, respectively. $g^{s}$ Follows the nonassociated flow rule, while $g^{t}$ follows the associated flow rule:
TABLE 1: Management value of track geometric irregularity in the UK.

\begin{tabular}{lcc}
\hline Control conditions & Wavelength $(\mathrm{m})$ & Versine $(\mathrm{mm})$ \\
\hline (1) Ride performance & 50.00 & 16.00 \\
& 20.00 & 9.00 \\
& 10.00 & 5.00 \\
\hline (2) Additional dynamic & 5.00 & 2.50 \\
load on the track & 2.00 & 0.60 \\
& 1.00 & 0.30 \\
\hline (3) Corrugated wear & 0.50 & 0.10 \\
& 0.05 & 0.005 \\
\hline
\end{tabular}

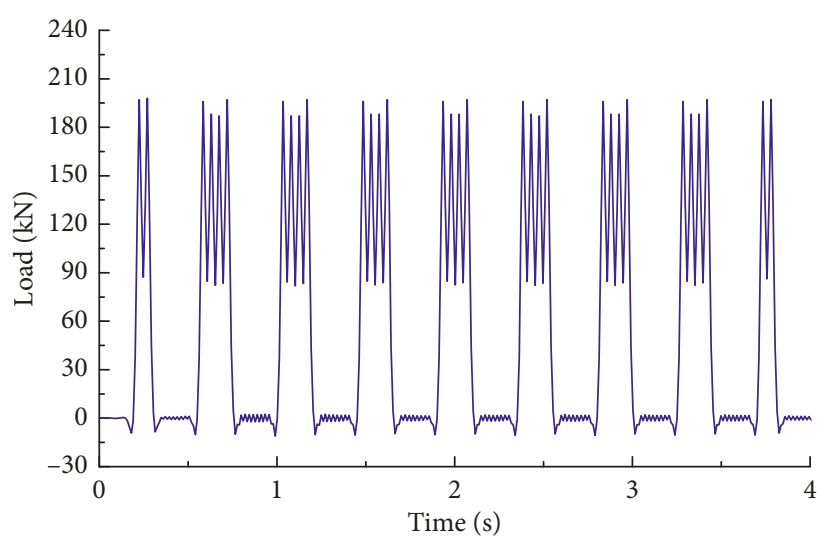

FIgURE 1: Time-history curve of train excitation load.

$$
\left\{\begin{array}{l}
g^{s}=\sigma_{1}-\sigma_{3} N_{\psi}, \\
g^{t}=-\sigma_{3}
\end{array}\right.
$$

where $\psi$ is the dilatancy angle and $N_{\psi}=1+\sin \phi / 1-\sin \phi$.

The function $h$ is defined in the $\sigma_{1}-\sigma_{3}$ stress plane:

$$
h=\sigma_{3}-\sigma^{t}+a_{p}\left(\sigma_{1}-\sigma^{p}\right),
$$

where $a^{p}=\sqrt{1+N_{\phi}^{2}}+N_{\phi}$ and $\sigma^{p}=\sigma^{t} N_{\phi}-2 c \sqrt{N_{\phi}}$.

The positive and negative zones indicated by the function $h$ are taken as the criteria for determining the tensile and shear plastic flow zones, as shown in Figure 2.

If the stress point falls into zone 1 , then the shear yield occurs, and the stress should be adjusted to the curve corresponding to the yield function $f^{s}=0$ according to the flow rule determined by the shear potential function $g^{s}$; if the stress point falls into zone 2, then the tensile yield occurs, and the stress should be adjusted to the curve corresponding to the yield function $f^{t}=0$ according to the flow rule determined by the tensile potential function $g^{t}$.

Composite lining is used for the tunnel support structure. C25 shotcrete is used for the primary support, C30 form concrete is used for the secondary lining, and the surrounding rocks are of red-bed soft rock. See Table 2 for the specific material parameters of the model.

2.2.2. Dynamic Boundary Condition. Viscous boundary, which was first proposed by Lysmer and Kuhlemeyer [32], is 


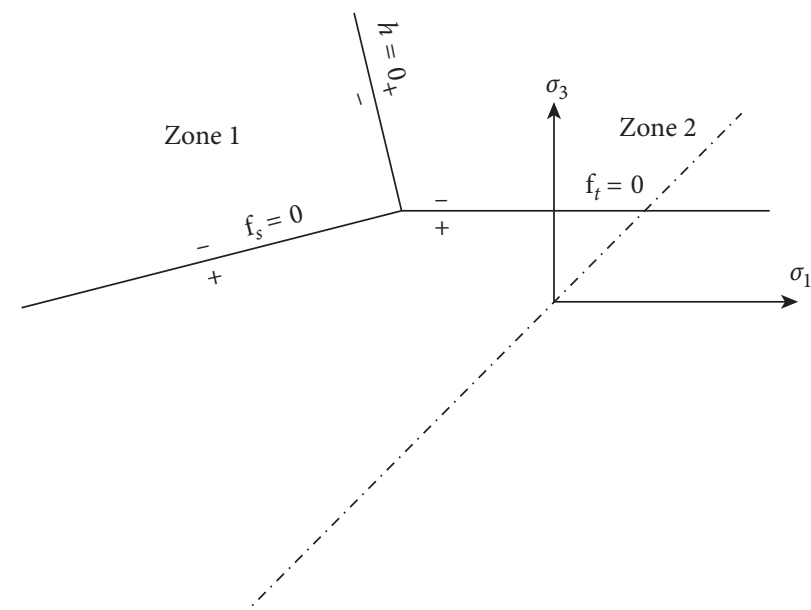

FIgURE 2: Schematic diagram for tensile and shear plastic flow zones in the Mohr-coulomb model.

TABLE 2: Physical mechanics properties of model.

\begin{tabular}{lccccc}
\hline Material type & Density $\left(\mathrm{kg} / \mathrm{m}^{3}\right)$ & Elastic modulus $(\mathrm{GPa})$ & Poisson's ratio & Friction Angle $\left(^{\circ}\right)$ & Cohesive force $(\mathrm{MPa})$ \\
\hline Subgrade & 2500 & 6 & 0.3 & 39 & 1 \\
Base slab & 2500 & 3.6 & 0.3 & 36 & 0.2 \\
Primary support & 2500 & 25.5 & 0.2 & 58.7 & 1.3 \\
Secondary lining & 2500 & 28 & 0.3 & 33 & 1.6 \\
Red-bed soft rock & 2150 & 3.6 & 33 & 0.45 \\
\hline
\end{tabular}

adopted as the boundary condition of the model. This condition is equivalent to the situation where independent dampers are separately set at the normal and tangential positions of the artificial boundary to absorb the scattered wave by dissipating the energy of the vibration wave with the generated viscous damping force proportional to the moving speed. This method is easy to be implemented in dynamic time-domain analysis, and its validity has been widely proved in finite element and finite difference methods. The normal and tangential forces provided by the dampers are

$$
\left\{\begin{array}{l}
t_{n}=-\rho C_{p} v_{n}, \\
t_{s}=-\rho C_{s} v_{s},
\end{array}\right.
$$

where $\rho$ is the density of rock mass media; $C_{p}$ and $C_{s}$ are the wave velocities of longitudinal and transverse waves in rock mass media, respectively; and $v_{n}$ and $v_{s}$ are the normal and tangential components of the particle vibration velocity due to fluctuations on the artificial boundary.

In the calculation model, a viscous boundary is applied to the bottom and the left and right boundaries, and normal constraint is imposed on the front and rear boundaries. The soil mass above the model is the free surface.

The depth of the tunnel is taken as $55.97 \mathrm{~m}$, and the height and width of the model are $100 \mathrm{~m}$. With reference to the wheel-rail excitation force function provided in Formula (1), the duration of train excitation load applied on the model is $3.5 \mathrm{~s}$. In the calculation of the train excitation load applied on the model, the concentrated force is converted into surface force loaded on the subgrade to simulate the train passing through the tunnel. See Figure 3 for the calculation model.

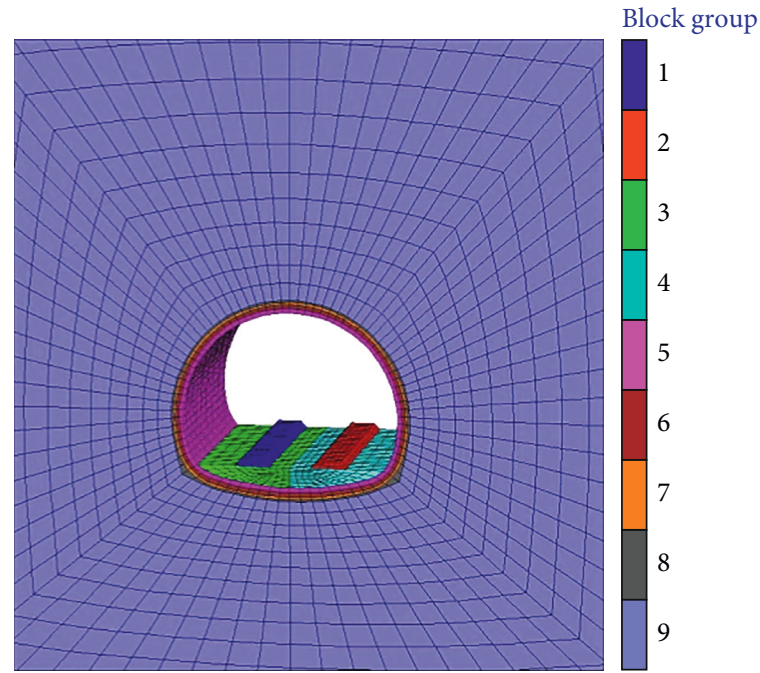

FIgURE 3: Numerical calculation model.

2.3. Analysis of Heavy-Haul Railway Tunnel with Voided Base. The structure of the tunnel base is in an initial state at the beginning. With the increased times of train load, the surrounding rock of the base is gradually voided. This may occur symmetrically from the position near the track (void condition 1) or from the center of the inverted arch (void condition 2). With the occurrence of the void, the base structure of the tunnel gradually cracks from elastic deformation. With the occurrence of cracks, combined with the weakened constraint on the structure caused by void, the base structure will be subjected to greater deformation 
under train load, and such deformation will accelerate the formation of void in turn (void condition 3). Due to continuous development of void, the support condition of the base structure keeps changing and the number of cracks keeps increasing. Such structural damage and void of base develop with and promote each other, finally resulting in failure of base structure. See Figure 4 for the evolution concept.

In order to analyze the influence of the base void (Figure 5) on the dynamic response of the base structure, the calculation model compares and analyzes 8 void cases, as shown in Table 3. The dynamic response of the structure caused by the train load is mainly at the inverted arch. Therefore, monitoring points are arranged near the inverted arch, the arch springing, and the void area of the tunnel, as shown in Figure 6.

2.4. Prediction Methods for Fatigue Life of Concrete. Fatigue refers to the structural change process in which the local permanent and progressive development of the material occurs under the condition that alternating stress and strain are applied on a certain point or at some points of the material. Fatigue failure is the result that the fatigue damage is accumulated to a critical value. It may cause the accumulation of cracks or the bending fracture of the material after certain times of alternating loads are applied [33]. The fatigue life refers to the cycle times that the material is applied with stress or strain before the fatigue failure appears, or the time between the beginning of the loading and the occurrence of the fracture.

Under the action of the cyclic load, the material damage of the base structure of heavy-haul railway tunnels is more and more serious, the material properties deteriorate gradually with the increase of cycle times, and thus the bearing capacity of the components decreases gradually and finally damage appears. The cumulative fatigue damage model of concrete can be established to predict the service life. The prediction can provide a reference for the evaluation of the residual service life of the base structure of the existing heavy-haul railway tunnel and the maintenance and reinforcement of the damaged structure. The existing methods for fatigue life prediction of concrete mainly include nominal stress method, energy method, local stress and strain method, and stress field intensity method. The most widely used method is the nominal stress method, which is also known as S-N curve method. This method is mainly applicable to the calculation of high-cycle fatigue life. The specific analytical steps of the nominal stress method are as follows:

(1) Determine the load spectrum and apply it to the structure to obtain the nominal stress spectrum of the structure

(2) Determine the fatigue dangerous part of the structure and its nominal stress spectrum

(3) Establish the S-N curve equation of the structure or component

(4) Determine the fatigue life of the structure

\section{Results and Discussion}

3.1. Effects on Displacement and Velocity of Base under Void Condition. The displacement and velocity response of tunnel structure under train load is mainly vertical, and the response of the inverted arch is the most intense. It is found that the displacement and velocity of the monitoring point $\mathrm{A}$ in the center of the inverted arch are the largest through monitoring the vertical displacement and velocity of each monitoring point. The point $\mathrm{A}$ is taken as the research object, the vertical displacement and velocity time-history curves under different void dimensions are extracted, as shown in Figures 7 and 8 .

Through the analysis on vertical displacement and velocity time-history curves for the inverted arch of the tunnel, the findings are as follows.

The effects of loading, unloading, and vibration generated by train passing cause the fluctuation of vertical displacement response at lining monitoring points. The peaks and valleys of the time-history curve for each response correspond to the rolling through effect of train wheels.

The vertical displacement and velocity curves of the inverted arch vary obviously with the increase of void width, which shows that the void width of the base under the rail has a great effect on the displacement and velocity of the inverted arch. However, such variation is minor with the increase of the void thickness, which shows that the void thickness of the base under the rail has little effect on the displacement of the inverted arch. The peak values of vertical displacement and velocity of the inverted arch in different cases are shown in Table 4.

The curves for relationship between the peak values of displacement and velocity of the inverted arch and the void area of the base are shown in Figures 9 and 10.

The peak value of vertical displacement of the inverted arch reaches $26 \mathrm{~mm}$, and the vertical velocity reaches $8.2 \mathrm{~cm} / \mathrm{s}$ when the void width of base reaches $6 \mathrm{~m}$. The vertical displacement is increased by about 9 times, and the peak value of velocity is increased by about 3.8 times, compared with the condition without void. Thus, it can be seen that the vertical displacement and velocity of the inverted arch are obviously affected by the void of base.

The curve variation trends in Figures 9 and 10 also prove that the void depth has a greater effect on the displacement and velocity responses of the base structure than the void thickness. The peak value variations for vertical displacement and velocity of inverted arch are around $1 \mathrm{~mm}$ and $0.4 \mathrm{~cm} / \mathrm{s}$, respectively, with the increase of void thickness. In order to verify the rationality of this result, the peak value of vertical displacement and velocity of the inverted arch is calculated in the case of void width of $12 \mathrm{~m}$ since the void width is almost impossible to be greater than $12 \mathrm{~m}$, and the calculation results are shown in Table 5 .

It can be seen from Table 5 that, in the case of a void width of $12 \mathrm{~m}$, displacement and velocity remain almost unchanged. Therefore, the void thickness has little effect on the peak value of displacement and velocity of the inverted arch when the void width is in the range between $5 \mathrm{~m}$ and $12 \mathrm{~m}$. 


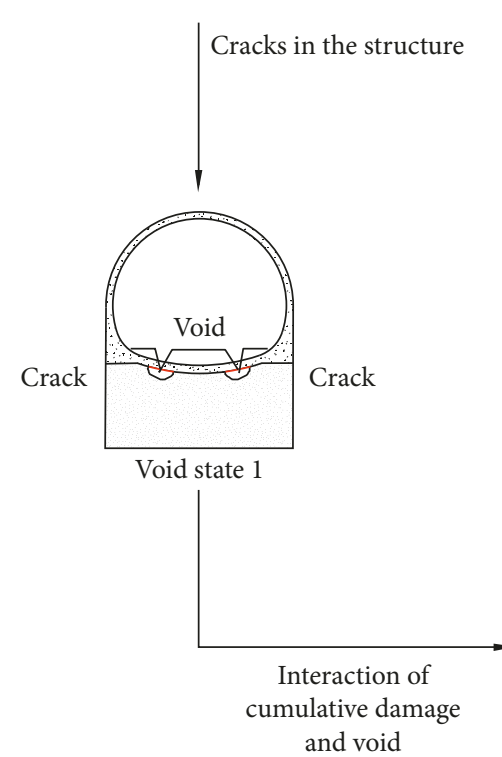

and void

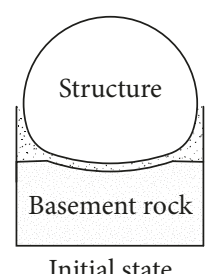

Initial state

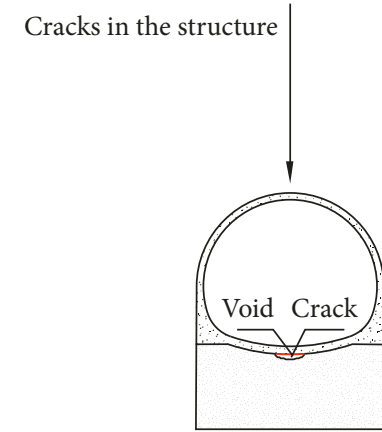

Void state 2

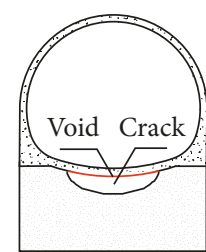

Void state 3

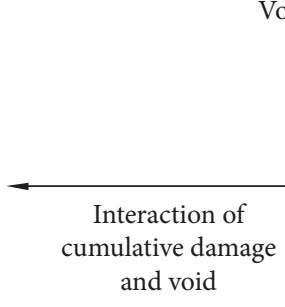

Figure 4: Concept diagram for formation and evolution of base void.

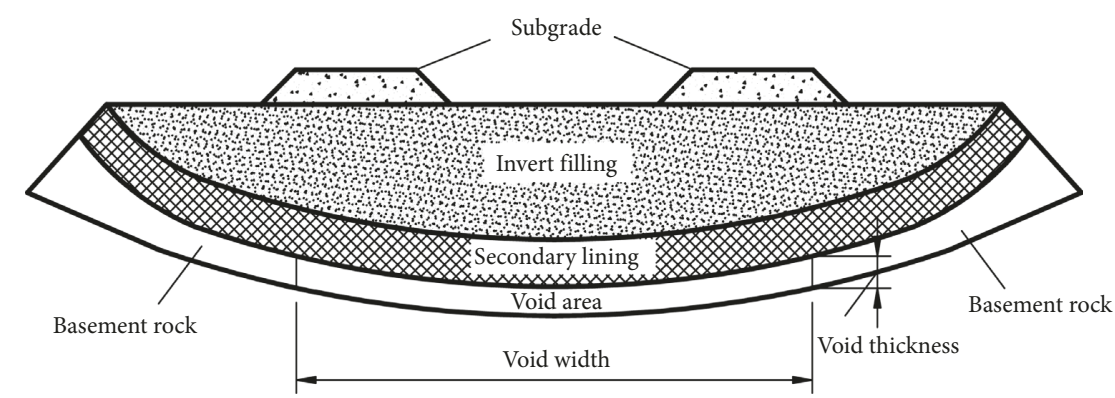

Figure 5: Schematic diagram for under-track base void of the tunnel.

TABle 3: Description of calculation cases of void.

\begin{tabular}{lccc}
\hline \multirow{2}{*}{$\begin{array}{l}\text { Calculation } \\
\text { cases }\end{array}$} & $\begin{array}{c}\text { Void } \\
\text { conditions }\end{array}$ & $\begin{array}{c}\text { Void dimensions } \\
\text { Void width } \\
(\mathrm{m})\end{array}$ & $\begin{array}{c}\text { Void thickness } \\
(\mathrm{m})\end{array}$ \\
\hline Case 1 & Base without void & - & - \\
Case 2 & Base with void & 2 & 10 \\
Case 3 & Base with void & 3 & 10 \\
Case 4 & Base with void & 4 & 10 \\
Case 5 & Base with void & 5 & 10 \\
Case 6 & Base with void & 6 & 10 \\
Case 7 & Base with void & 4 & 20 \\
Case 8 & Base with void & 4 & 30 \\
\hline
\end{tabular}

3.2. Effects on Maximum Principal Stress of Base under Void Condition. The curves for maximum principal stress at the inverted arch in different cases are shown in Figure 11.

As shown in Figure 11, the response curve of maximum principal stress of the inverted arch varies greatly with the

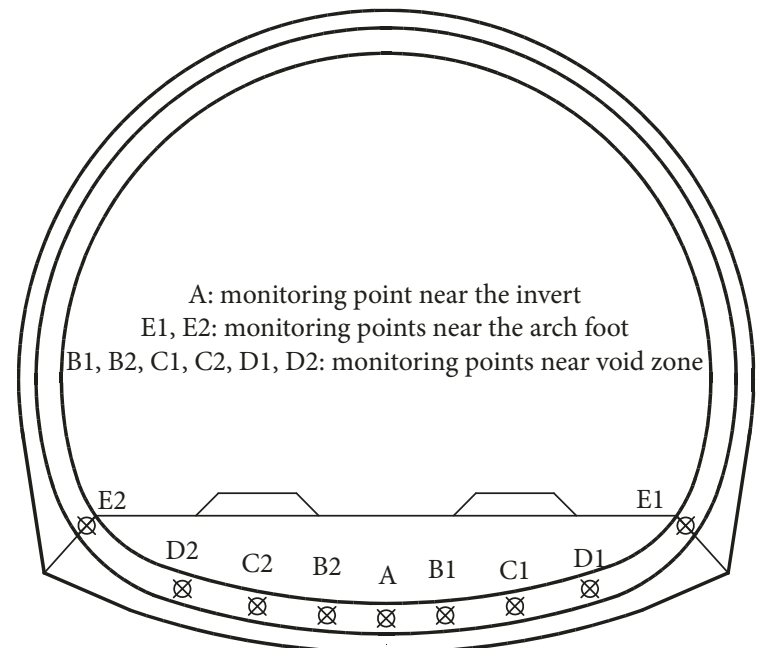

FIgURE 6: Schematic diagram for arrangement of monitoring points of structure. 


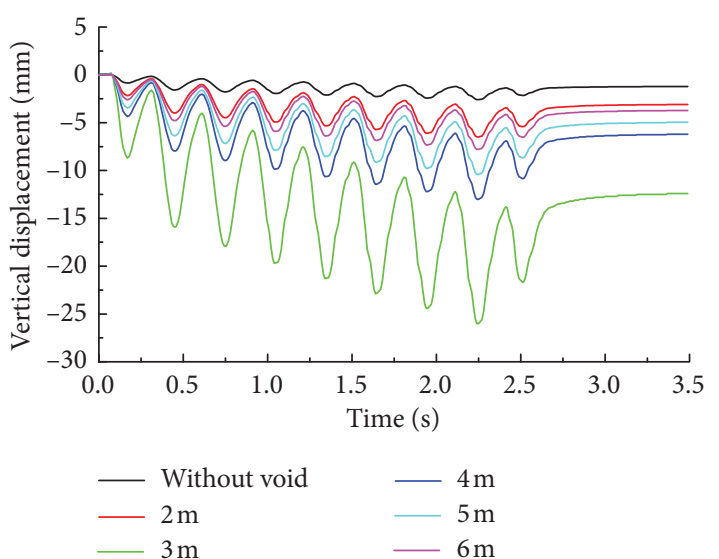

(a)

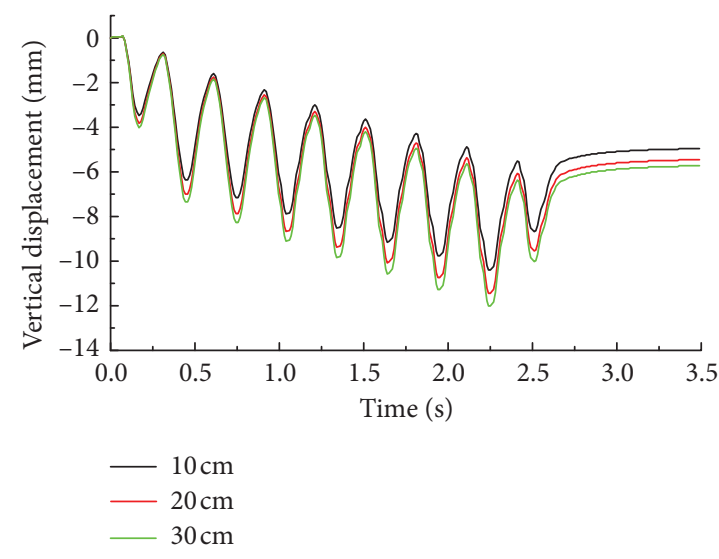

(b)

Figure 7: Time-history curves for vertical displacement of the inverted arch. (a) Vertical displacement of the inverted arch under different void widths (with a void thickness of $10 \mathrm{~cm}$ ). (b) Vertical displacement of the inverted arch under different void thicknesses (with a void width of $4 \mathrm{~m})$.

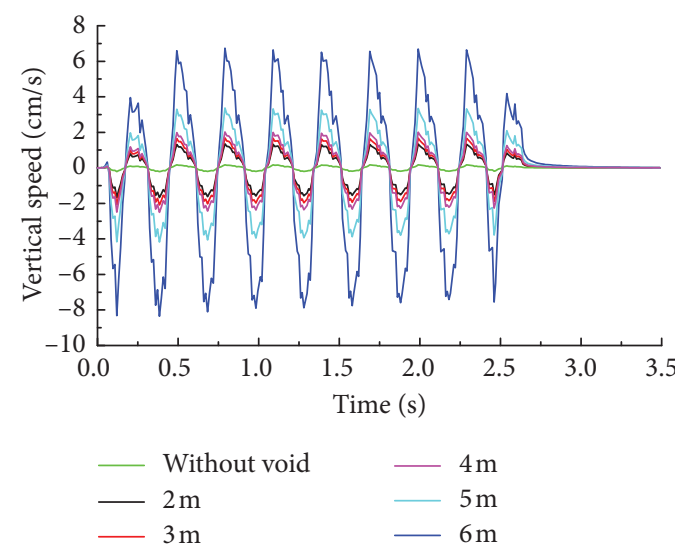

(a)

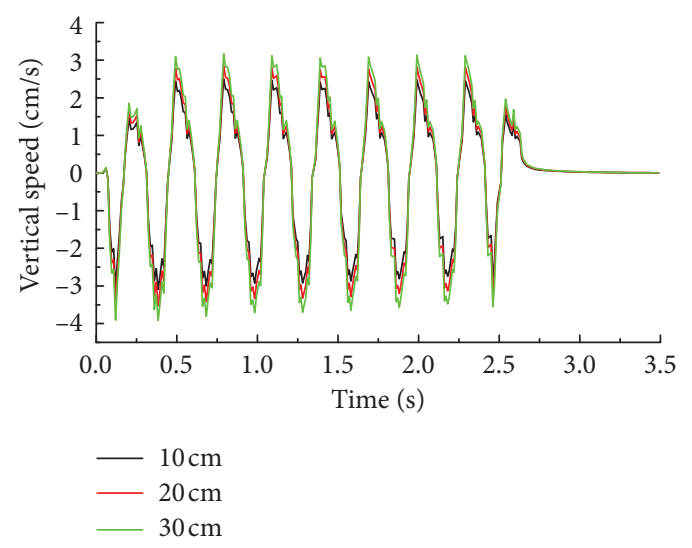

(b)

FIGURE 8: Time-history curves for vertical velocity of the inverted arch under different void cases. (a) Vertical velocity of the inverted arch under different void widths (with a void thickness of $10 \mathrm{~cm}$ ). (b) Vertical velocity of the inverted arch under different void thicknesses (with a void width of $4 \mathrm{~m}$ ).

TABLe 4: Peak values of vertical displacement and velocity of the inverted arch.

\begin{tabular}{|c|c|c|c|c|c|}
\hline \multirow{2}{*}{ Case } & \multirow{2}{*}{ Void conditions } & \multicolumn{2}{|c|}{ Void dimensions } & \multirow{2}{*}{ Peak value of vibration displacement $(\mathrm{cm})$} & \multirow{2}{*}{ Peak value of velocity $(\mathrm{cm} / \mathrm{s})$} \\
\hline & & Void width (m) & Void thickness $(\mathrm{cm})$ & & \\
\hline 1 & Without void & - & - & -0.26 & -1.67 \\
\hline 2 & Void & 2 & 10 & -0.61 & -2.1 \\
\hline 3 & Void & 3 & 10 & -0.84 & -2.5 \\
\hline 4 & Void & 4 & 10 & -1.04 & -3.1 \\
\hline 5 & Void & 5 & 10 & -1.27 & -4.4 \\
\hline 6 & Void & 6 & 10 & -2.6 & -8.2 \\
\hline 7 & Void & 4 & 20 & -1.14 & -3.5 \\
\hline 8 & Void & 4 & 30 & -1.2 & -3.9 \\
\hline
\end{tabular}

increase of void width, which shows that the void width of the base under the rail has a great effect on the principal stress of the inverted arch. However, the curve varies slightly with the increase of the void thickness, which shows that the void thickness of the base under the rail has little effect on the principal stress of the inverted arch.
The peak values of the maximum principal stress of the inverted arch in different cases are shown in Table 6. The variation of the peak value corresponding to the expansion of the void area of base is shown in Figure 12.

It can be seen from Table 6 and Figure 12 that the maximum principal stress of the inverted arch is affected 


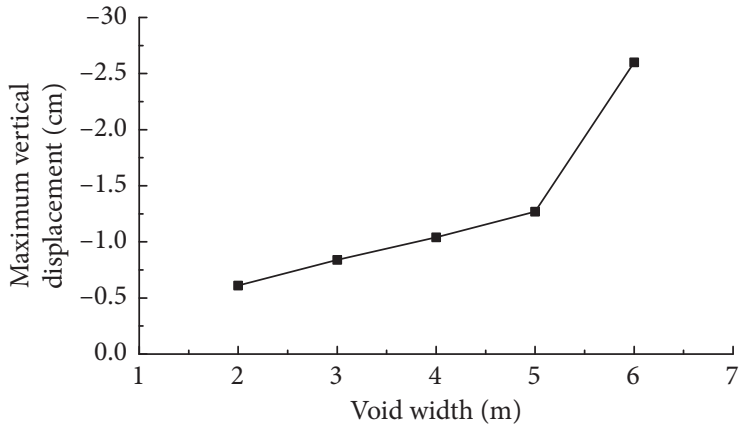

(a)

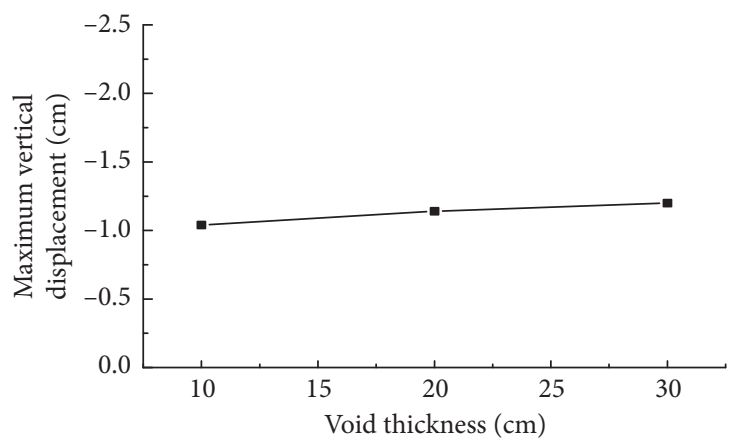

(b)

Figure 9: Peak value variation curve for vertical displacement of the inverted arch: (a) void thickness is $10 \mathrm{~cm}$; (b) void width is $4 \mathrm{~m}$.

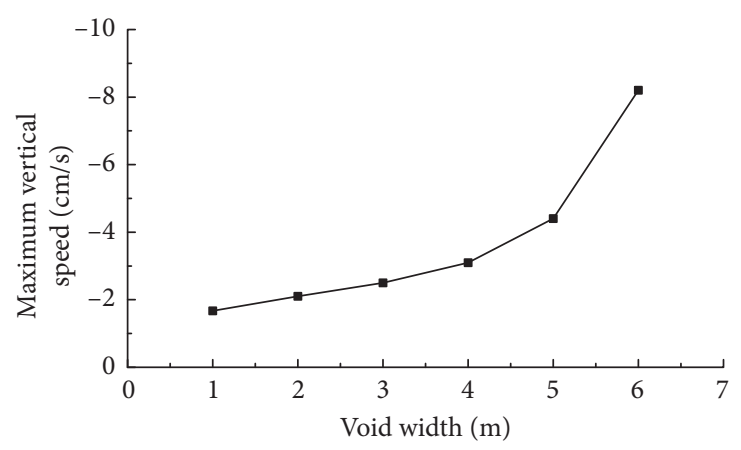

(a)

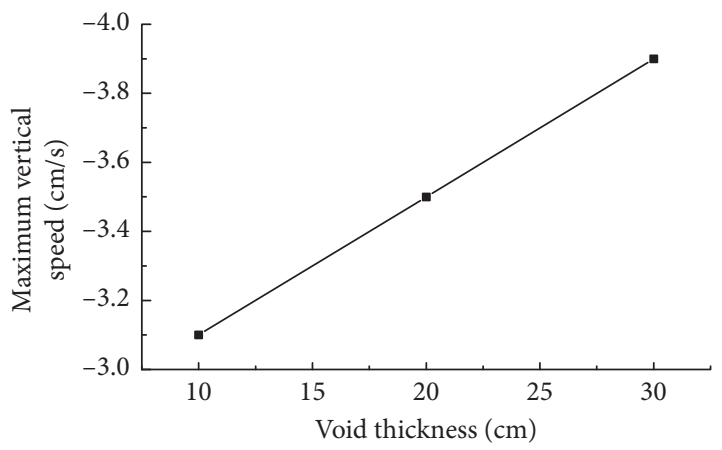

(b)

FIgURE 10: Peak value variation curve for vertical velocity of the inverted arch: (a) void thickness is $10 \mathrm{~cm}$; (b) void width is $4 \mathrm{~m}$.

Table 5: Peak value of vertical displacement and velocity (in the case of void width of $12 \mathrm{~m}$ ).

\begin{tabular}{|c|c|c|c|c|}
\hline \multirow{2}{*}{ Void conditions } & \multicolumn{2}{|c|}{ Void dimensions } & \multirow{2}{*}{ Peak value of displacement $(\mathrm{cm})$} & \multirow{2}{*}{ Peak value of velocity $(\mathrm{cm} / \mathrm{s})$} \\
\hline & Void width (m) & Void thickness $(\mathrm{cm})$ & & \\
\hline Void & 12 & 15 & -4.2 & -12.6 \\
\hline Void & 12 & 20 & -4.3 & -12.8 \\
\hline Void & 12 & 25 & -4.3 & -12.9 \\
\hline
\end{tabular}

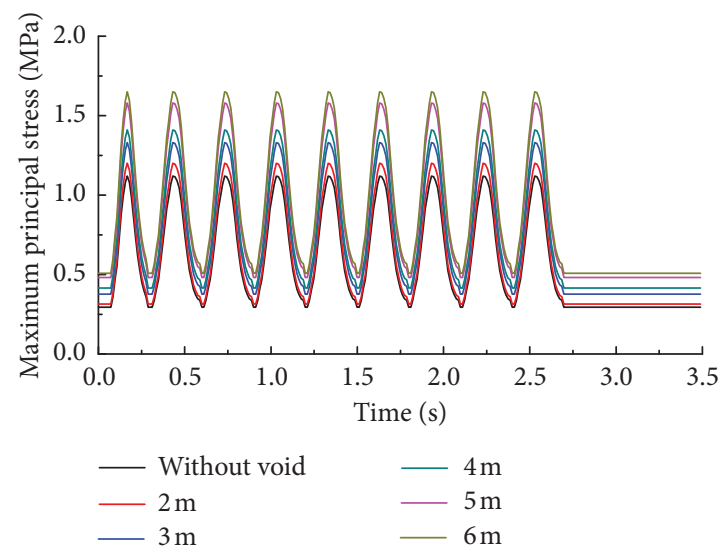

(a)
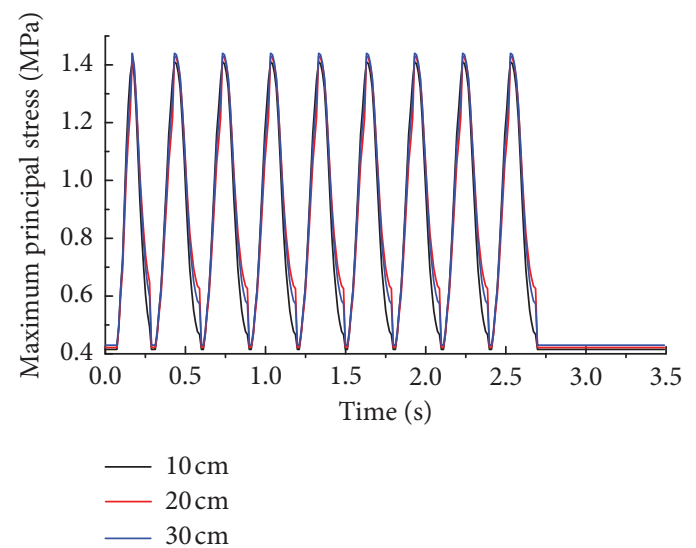

(b)

FIGURE 11: Time-history curves for maximum principal stress at the inverted arch. (a) Maximum principal stress of the inverted arch under different void widths (with a void thickness of $10 \mathrm{~cm}$ ). (b) Maximum principal stress of the inverted arch under different void thicknesses (with a void width of $4 \mathrm{~m}$ ). 
TABLE 6: Peak values of maximum principal stress of the inverted arch (MPa).

\begin{tabular}{lcccccccc}
\hline Case & Case 1 & Case 2 & Case 3 & Case 4 & Case 5 & Case 6 & Case 7 & Case 8 \\
\hline Peak values of maximum principal stress & 1.12 & 1.20 & 1.33 & 1.41 & 1.58 & 1.65 & 1.43 & 1.44 \\
\hline
\end{tabular}

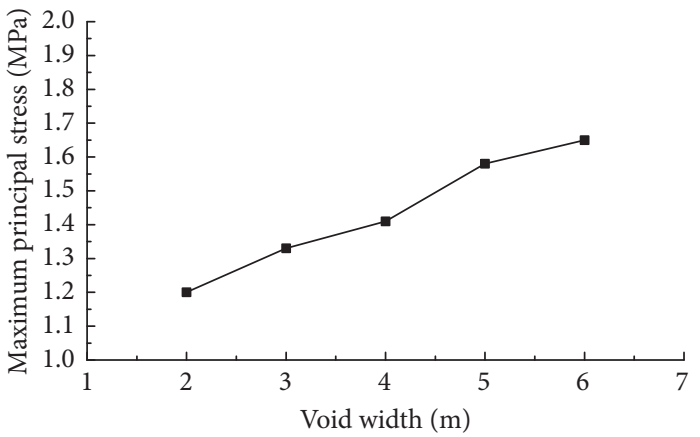

(a)

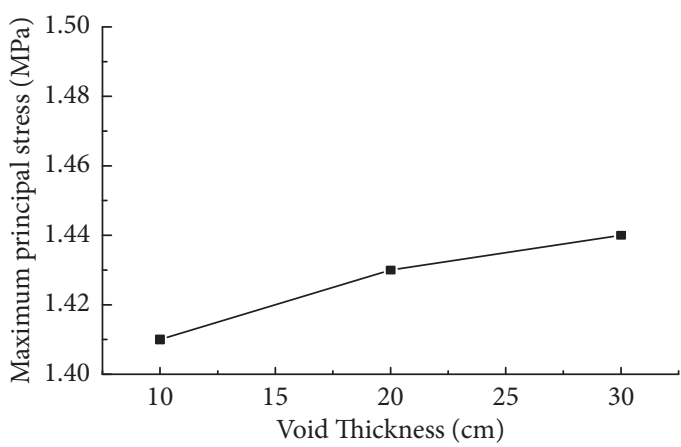

(b)

FIGURE 12: Peak value variation curve for maximum principal stress of the inverted arch: (a) void thickness is $10 \mathrm{~cm}$; (b) void width is $4 \mathrm{~m}$.

obviously by the void of base under the rail and that the maximum principal stress of the inverted arch varies obviously with the increase of the void width. The peak value of maximum principal stress of the inverted arch reaches $1.65 \mathrm{MPa}$ when the void width of the base reaches $6 \mathrm{~m}$, increased by $0.53 \mathrm{MPa}$ compared with the condition without void. Thus, it can be seen that the maximum principal stress of the inverted arch is affected obviously by the void width of the base. The peak value variation for maximum principal stress of the inverted arch is around $0.02 \mathrm{MPa}$ with the gradual increase of void thickness. Like the displacement and velocity, the maximum principal stress of the inverted arch in the case of void width of $12 \mathrm{~m}$ is also obtained in Table 7.

Table 7 indicates that when the void width is $12 \mathrm{~m}$, the peak value of maximum principal stress of the inverted arch is approximately $2.4 \mathrm{MPa}$ regardless of the void thickness. Thus, it can be seen that void thickness has little effect on the peak value of principal stress of the inverted arch when the void width is in the range between $5 \mathrm{~m}$ and $12 \mathrm{~m}$.

\subsection{Analysis on Fatigue Life of Heavy-Haul Railway Tunnel} Structure under Train Vibration. It can be concluded through the analysis in the previous sections that the heavyhaul railway tunnel structure has the most obvious dynamic response at the inverted arch. Meanwhile, based on the analysis of the maximum principal stress, the structure is subjected to tensile stress at the inverted arch only, and it is subjected to compressive stress at other parts. The level of compressive stress is small for concrete, and it is generally considered that it will not cause fatigue failure. Therefore, the part that ultimately controls the fatigue life of heavy-haul railway tunnel structure under train load is the part where the inverted arch is subjected to tensile stress, and the maximum stress of this part has been determined.

The most important step in the nominal stress method is to determine the fatigue life $\mathrm{S}-\mathrm{N}$ curve of the structure or
TABLE 7: Peak value of maximum principal stress (in the case of void width of $12 \mathrm{~m}$ ).

\begin{tabular}{lccc}
\hline Void \\
conditions & $\begin{array}{c}\text { Void } \\
\text { width } \\
(\mathrm{m})\end{array}$ & $\begin{array}{c}\text { Void thickness } \\
(\mathrm{cm})\end{array}$ & $\begin{array}{c}\text { Peak values of } \\
\text { maximum } \\
\text { principal stress }(\mathrm{MPa})\end{array}$ \\
\hline Void & 12 & 15 & 2.44 \\
Void & 12 & 20 & 2.47 \\
Void & 12 & 25 & 2.49 \\
\hline
\end{tabular}

component. At present, the fatigue performance data of all kinds of components are obtained by a large number of tests so that the S-N curve is determined. Many scholars have studied the fatigue performance of concrete material in tension. Tepfers et al. [34] put forward an equation similar to that of concrete compressive fatigue to describe concrete tensile fatigue on the basis of fatigue tests such as axial tension and splitting, as shown in the following formula:

$$
S_{t \max }=a_{t}-b_{t}\left(1-R_{t}\right) \lg N,
$$

where $S_{t \max }=\sigma_{t \max } / f_{t}, R_{t}=\sigma_{t \min } / \sigma_{t \max } ; \sigma_{t \max }$ : upper limit value of fatigue tensile stress; $\sigma_{t \text { min }}$ : lower limit value of fatigue tensile stress; $f_{t}$ : static axial tensile strength of concrete; $a_{t}, b_{t}$ : coefficients determined by the fatigue test, which are generally taken as $a_{t}=1.0$ and $b_{t}=0.0685$; and $N$ : limit loading times.

The above equation is more accurate in describing the fatigue life of concrete under axial tension. But the base of heavy-haul railway tunnels is a structure subjected to bending tension, and its stress condition is more complicated than a structure subjected to axial tension. Sidoroff et al. [35] have proved that the above formula is also applicable to the bending tensile fatigue $\mathrm{S}-\mathrm{N}$ curve of concrete, but the taken value of the coefficient in the fatigue test is different. The bending tensile fatigue equation of concrete is obtained as follows [36, 37]: 
TABLE 8: Maximum principal stress of the inverted arch in different cases (MPa).

\begin{tabular}{lcccccccccc}
\hline Case & & Case 1 & Case 2 & Case 3 & Case 4 & Case 5 & Case 6 & Case 7 & Case 8 \\
\hline \multirow{2}{*}{ Maximum principal stress } & Max & 1.12 & 1.2 & 1.33 & 1.41 & 1.58 & 1.65 & 1.43 & 1.44 \\
& Min & 0.295 & 0.314 & 0.376 & 0.415 & 0.481 & 0.508 & 0.422 & 0.430 \\
\hline
\end{tabular}

TABle 9: Statistical list of fatigue life in various cases.

\begin{tabular}{lcccccccc}
\hline & Case 1 & Case 2 & Case 3 & Case 4 & Case 5 & Case 6 & Case 7 & Case 8 \\
\hline $\lg N$ & 8.80 & 8.05 & 6.85 & 6.10 & 4.53 & 3.88 & 5.92 & 5.83 \\
$N$ & $6.31 E 8$ & $1.12 E 8$ & $7.08 E 6$ & $1.25 E 6$ & $3.39 E 4$ & $7.59 E 3$ & $8.32 E 5$ & $6.76 E 5$ \\
\hline
\end{tabular}

$$
S_{r \max }=a_{r}-b_{r} \lg N
$$

where $S_{r \text { max }}=\sigma_{r \text { max }} / f_{r} ; \sigma_{r \text { max }}$ : maximum tensile stress of concrete at lower edge under constant-amplitude repeated load; $\sigma_{t \text { min }}$ : lower limit value of fatigue tensile stress; $f_{r}$ : static bending tensile strength of concrete; $a_{r}, b_{r}$ : coefficients determined by the fatigue test, which are generally taken as $a_{r}=0.94-1.35$ and $b_{r}=0.045-0.118$.

The time-history curves for the maximum principal stress of the inverted arch under different void conditions have been obtained through the calculation and analysis for the dynamic response of the structure under different void conditions. Table 8 shows the statistical results of the maximum and minimum values.

The maximum and minimum values of the maximum principal stress are, respectively, regarded as the maximum and the minimum values of the tensile stress of the structure. The bending tensile fatigue life of the concrete is calculated with the formula (10), where $a_{r}=0.94$ and $b_{r}=0.049$. Raphael et al. [38] has proved that the bending tensile strength of concrete is generally $35 \%$ higher than the straight tensile strength based on many test results. Therefore, the fatigue life of concrete is calculated by taking $f_{r}=2.2 \mathrm{MPa}$ and setting Case 1 as the example:

$$
\begin{gathered}
S_{r \max }=\sigma_{r \max } / f_{t}=\frac{1.12}{2.2}=0.509, \\
\lg N=\frac{0.94-0.509}{0.049}=8.80,
\end{gathered}
$$

The load action times corresponding to the fatigue failure:

$$
N=6.31 \times 10^{8}
$$

Thus, it can be seen from the above calculation that the fatigue life of the structure under the condition without void is longer.

Similarly, the calculation results of the rest of the cases are statistically shown in Table 9. The variation of fatigue life in different cases is shown in Figure 13.

It can be seen from Table 9 and Figure 13 that the void width of the base has an obvious effect on the fatigue life of heavy-haul railway tunnel structure, and the fatigue life of the structure decreases sharply especially in the early stage of void development. The variation of fatigue life tends to be gentle when the void width reaches a certain value. It can be

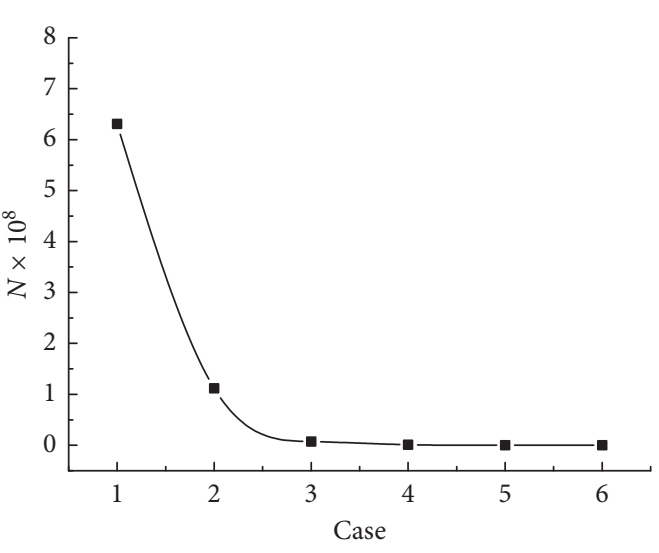

(a)

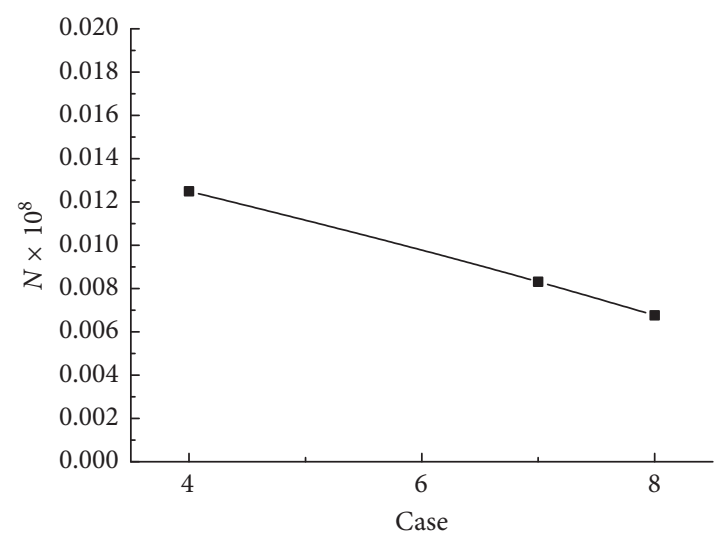

(b)

FIGURE 13: Law curve for structure fatigue life varying with base void range.

seen from Case 3 that the action times of fatigue load for the structure is only $7.08 \times 10^{6}$ when the void reaches $3 \mathrm{~m}$. If it is still estimated as per that the wheel set load of the Datong-Qinhuangdao Railway is 1,000 times per day, the service life of the tunnel is only 19.40 years. The allowable ultimate void width of base is $2 \mathrm{~m}$ based on the operation requirement of 100-year service life.

The void thickness of the base will not have an obvious effect on the service life of the heavy-haul railway tunnel structure with certain void width, and the fatigue life of the structure is maintained at a longer level. 


\section{Conclusions}

In this paper, the dynamic response characteristics of the heavy-haul railway tunnel structure under repeated impacts are studied based on the three-dimensional numerical dynamics coupling model of dynamic load-tunnel-surrounding rock, and the fatigue life of the tunnel structure under different void conditions is predicted based on the S-N curve of concrete. The main conclusions are as follows:

(1) The effects of loading, unloading, and vibration generated by train passing cause the fluctuation of vertical displacement response at lining monitoring points. The peaks and valleys of the time-history curve for each response correspond to the rolling through effect of train wheels.

(2) The dynamic response of base with void is much larger than that without void: When the void width is $6 \mathrm{~m}$ and the void thickness is $10 \mathrm{~cm}$, the vertical displacement of the inverted arch is about 10 times that under the condition without void, the peak velocity is about 4.9 times that under the condition without void, and the maximum principal stress is increased by about $47.3 \%$.

(3) The dynamic response of base is greatly affected by the void width under the condition of base with void. With the same void thickness, when the void width is $6 \mathrm{~m}$, the peak values of displacement and velocity of the inverted arch are, respectively, about 4.26 and 3.90 times the values when the void width is $2 \mathrm{~m}$.

(4) The void width of base has an obvious effect on the fatigue life of the heavy-haul railway tunnel structure. The ultimate void width is $2 \mathrm{~m}$ according to the S-N curve of concrete under bending tensile condition and based on the operation requirement of 100-year service life.

\section{Data Availability}

The data used to support the findings of this study are available from the corresponding author upon request.

\section{Conflicts of Interest}

The authors declare that there are no conflicts of interests regarding the publication of this paper.

\section{Acknowledgments}

The authors are very grateful for the funding from the National Key Research and Development Program of China (2016YFC0802202) and the General Program of National Natural Science Foundation of China (51678503).

\section{References}

[1] H. H. Jenkins, J. E. Stephenson, G. A. Clayton, G. W. Morland, and D. Lyon, "The effect of track and vehicle parameters on wheel/rail vertical dynamic forces," Railway Engineering Journal, vol. 3, no. 1, pp. 2-16, 1974.
[2] G. Lamaran and M. Derdas, "Evaluation of dynamics load on rail track sleepers based on vehicle-track modeling and analysis," International Journal of Structural Stability, vol. 2, no. 3, 2002.

[3] K. One and M. Yamada, "Analysis of railway track vibration," Journal of Sound and Vibration, vol. 130, no. 2, pp. 269-297, 1989.

[4] J. Lai, S. He, J. Qiu et al., "Characteristics of seismic disasters and aseismic measures of tunnels in Wenchuan earthquake," Environmental Earth Sciences, vol. 76, no. 94, 2017.

[5] J. Qiu, X. Wang, and J. Lai, "Response characteristics and preventions for seismic subsidence of loess in Northwest China," Natural Hazards, vol. 92, no. 3, pp. 1909-1935, 2018.

[6] A. V. Metrikine and A. C. W. M. Vrouwenvelder, "Surface ground vibration due to moving train in a tunnel: twodimensional model," Journal of Sound and Vibration, vol. 234, no. 1, pp. 43-66, 2000.

[7] T. Balendra, C. G. Koh, and Y. C. Ho, "Dynamic response of buildings due to trains in underground tunnels," Earthquake Engineering and Structural Dynamics, vol. 20, no. 3, pp. 275-291, 1991.

[8] J. A. Forrest and H. E. M. Hunt, "A three-dimensional model for calculation of train-induced ground vibration," Journal of Sound and Vibration, vol. 294, no. 1, pp. 678-705, 2006.

[9] J. A. Forrest and H. E. M. Hunt, "Ground vibration generated by trains in underground tunnels," Journal of Sound and Vibration, vol. 294, no. 4, pp. 706-736, 2006.

[10] M. F. M. Hussein and H. E. M. Hunt, "A numerical model for calculating vibration from a railway tunnel embedded in a full-space," Journal of Sound and Vibration, vol. 305, no. 3, pp. 401-431, 2007.

[11] R. Thiede and H. G. Natke, "The influence of thickness variation of subway walls on the vibration emission generated by subway traffic," in Proceedings of Soil Dynamics and Earthquake Engineering $V$ : International Conference Soil Dynamics and Earthquake Engineering, Karlsruhe, Germany, September 1991.

[12] F. Guan and I. D. Moore, "Three-dimensional dynamic response of twin cavities due to traveling loads," Journal of Engineering Mechanics, vol. 120, no. 3, pp. 637-651, 1994.

[13] K. H. Chua, K. W. Lo, and T. Balendra, "Building response due to subway train traffic," Journal of Geotechnical Engineering, vol. 121, no. 11, pp. 747-754, 1995.

[14] L. M. Peng, C. H. Shi, J. Huang, and S. L. Liu, "Study on the fatigue life of the tunnel bed structure under train loads," Journal of the China Railway Society, no. 1, pp. 82-85, 2007.

[15] L. M. Peng, L. C. Huang, and S. L. Liu, "Study on dynamic response of railway tunnel bedding structure," Journal of Vibration and Shock, vol. 25, no. 5, pp. 175-179, 2006.

[16] D. Clouteau, M. Arnst, T. M. G. Al-Hussaini et al., "Freefield vibrations due to dynamic loading on a tunnel embedded in a stratified medium," Journal of Sound and Vibration, vol. 283, no. 1, pp. 173-199, 2005.

[17] Z. Zhang, X. Shi, X. Wang, and H. Li, "Stability of NATM tunnel faces in soft surrounding rocks," Computers and Geotechnics, vol. 96, pp. 90-102, 2018.

[18] Z. Zhang, H. Li, H. Yang, and B. Wang, "Failure modes and face instability of shallow tunnels under soft grounds," International Journal of Damage Mechanics, article 105678951877313, 2018.

[19] Z. P. Bazant and H. O. Byung, "Strain-rate effect in rapid triaxial loading of concrete," ACI Materials Journal, vol. 180, pp. 764-782, 1982. 
[20] J. Mazars, "Description of micro- and macroscale damage of concrete structures," Engineering Fracture Mechanics, vol. 25, no. 5-6, pp. 729-737, 1985.

[21] M. N. Fardis and E. S. Chen, "A cyclic multiaxial model for concrete," Computational Mechanics, vol. 1, no. 4, pp. 301$315,1986$.

[22] T. M. Abu-Lebdeh, "Plasticity-damage model for concrete under cyclic multiaxial loading," Journal of Engineering Mechanics, ASCE, vol. 119, no. 7, pp. 1465-1485, 1993.

[23] J. Y. Wu, J. L. Li, and F. Rui, "An energy release rate-based plastic-damage model for concrete," International Journal of Solids and Structures, vol. 43, no. 3, pp. 583-612, 2006.

[24] L. M. Peng, N. Liu, and C. H. Shi, "Experimental study on dynamic amplitudes for cumulate damage characteristics of tunnel invert concrete," Journal of Railway Science and Engineering, vol. 13, no. 6, pp. 1091-1099, 2016.

[25] S. M. Wang, X. B. Li, F. Q. Gong, and J. J. Zhu, "Experimental study on mechanical properties of different ages concrete under static and dynamic load," Engineering Mechanics, vol. 30, no. 2, pp. 143-149, 2013.

[26] Q. Yan, H. Chen, W. Chen et al., "Dynamic characteristic and fatigue accumulative damage of a cross shield tunnel structure under vibration load," Shock and Vibration, vol. 2018, pp. 1-14, 2004.

[27] J. Qiu, X. Wang, S. He et al., "The catastrophic landside in Maoxian county, Sichuan, SW China, on June 24, 2017," Natural Hazards, vol. 89, no. 3, pp. 1485-1493, 2017.

[28] J. Qiu, Y. Xie, H. Fan, Z. Wang, and Y. Zhang, "Centrifuge modelling of twin-tunnelling induced ground movements in loess strata," Arabian Journal of Geosciences, vol. 10, no. 493, pp. 1-14, 2017.

[29] T. M. Dawn and C. G. Stanworth, "Ground vibrations from passing trains," Journal of Sound and Vibration, vol. 66, no. 3, pp. 355-362, 1979.

[30] C. Pan and G. N. Pande, "Preliminary deterministic finite element study on a tunnel driven in loess subjected to train loading," China Civil Engineering Journal, vol. 17, no. 4, pp. 19-28, 1984.

[31] B. Liang, The Dynamic Characteristics of High Speed Railway Subgrade and Geosynthetics' Applications, PhD Dissertation, Southwest Jiaotong University, Chengdu, China, 1998.

[32] J. Lysmer and R. L. Kuhlemeyer, "Finite dynamic model for infinite media," Journal of the Engineering Mechanics, ASCE, vol. 95, no. 4, pp. 859-877, 1969.

[33] J. M. Hanson, C. A. Ballinger, and D. Linger, "Considerations for design of concrete structures, subjected to fatigue loading," ACI Structural Journal, vol. 71, 1974.

[34] R. Tepfers, "Tensile fatigue strength of plain concrete," Journal of the American Concrete Institute, vol. 76, no. 8, pp. 919-933, 1979.

[35] F. Sidoroff, Description of Anisotropic Damage Application to Elasticity, pp. 237-244, Springer, Heidelberg, Germany, 1981.

[36] J. W. Murdock and C. E. Kesler, "Effect of range of stress on fatigue strength of plain concrete beams," Journal of American Concrete Institute, vol. 55, no. 2, pp. 221-232, 1959.

[37] B. H. Oh, "Fatigue analysis of plain concrete in flexure," Journal of Structural Engineering, vol. 112, no. 2, pp. 273-288, 1986.

[38] J. M. Raphael, "Tensile strength of concrete," Journal of the American Concrete Institute, vol. 81, no. 2, pp. 158-165, 1984. 


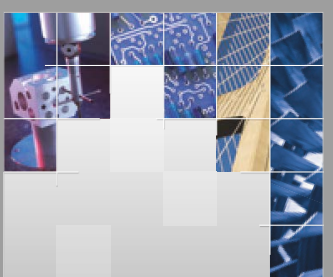

\section{Enfincering}
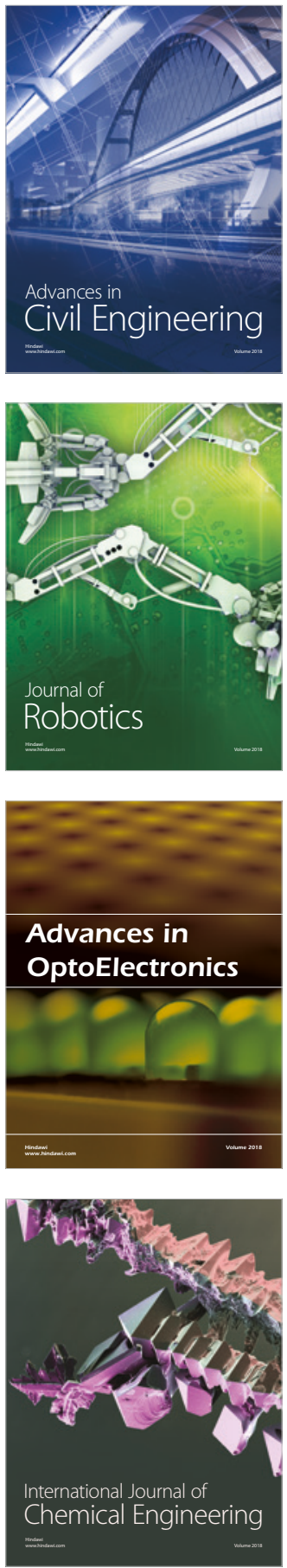

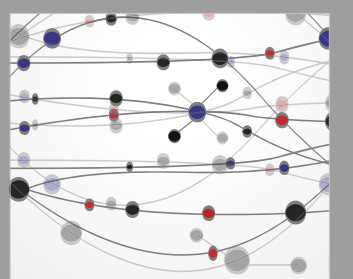

\section{Rotating \\ Machinery}

The Scientific World Journal

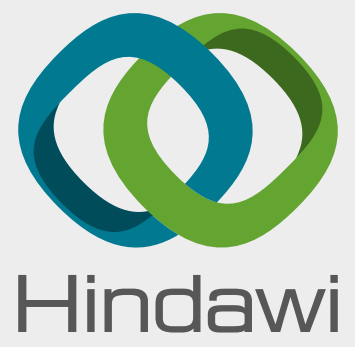

Submit your manuscripts at

www.hindawi.com
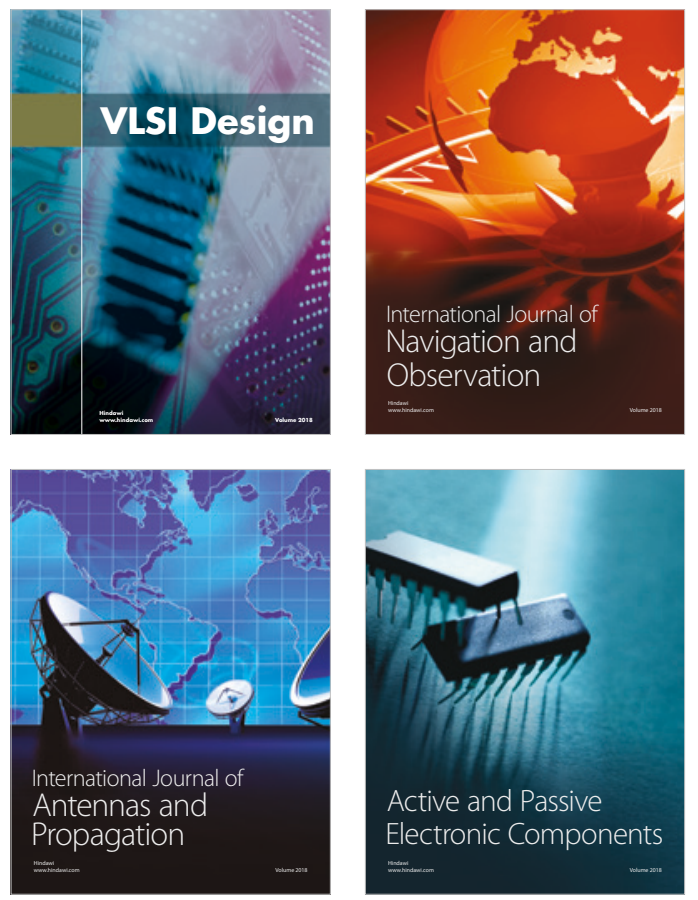
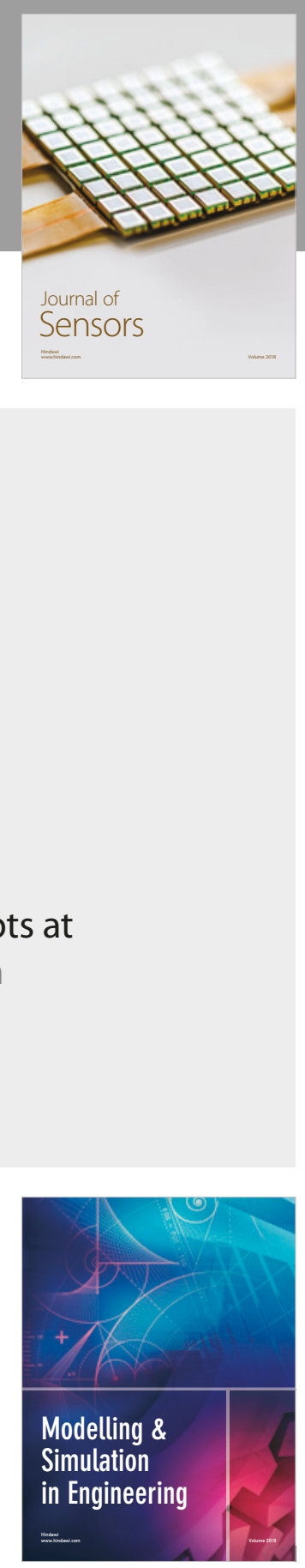

\section{Advances \\ Multimedia}
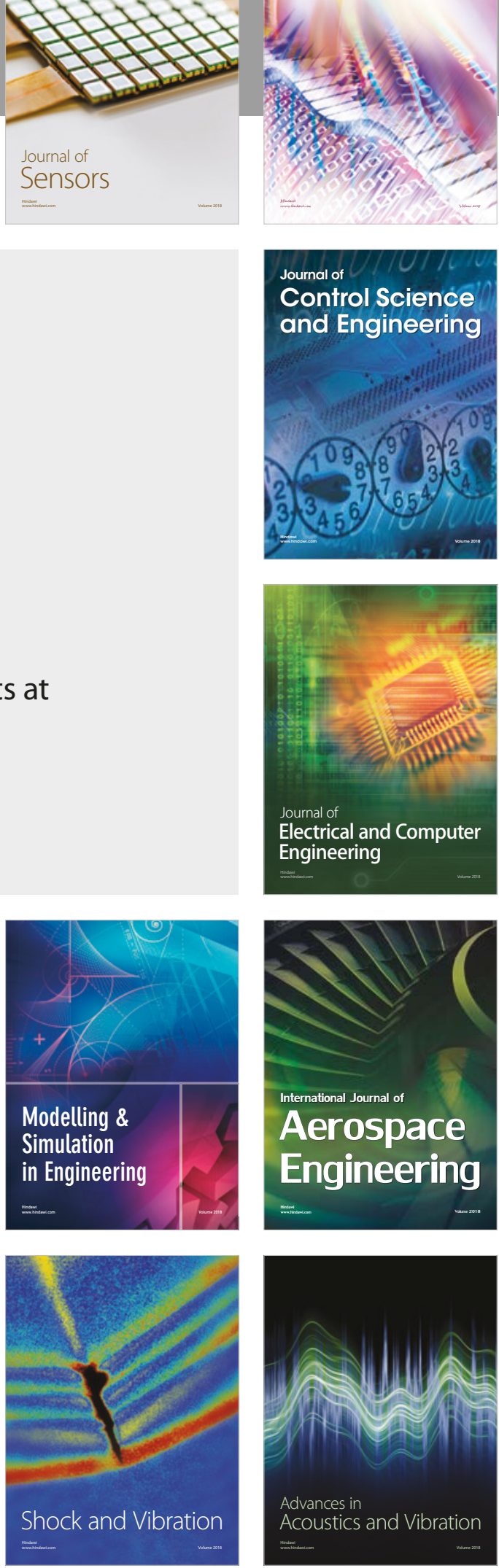